\title{
The non-antibiotic macrolide EM900 attenuates HDM and poly(I:C)-induced airway inflammation with inhibition of macrophages in a mouse model
}

\author{
Hironori Sadamatsu ${ }^{1} \cdot$ Koichiro Takahashi $^{1}\left[\right.$. Hiroki Tashiro ${ }^{1} \cdot$ Go Kato $^{1} \cdot$ Yoshihiko Noguchi $^{2} \cdot$ Keigo Kurata $^{3}$. \\ Satoshi Ōmura ${ }^{2} \cdot$ Shinya Kimura $^{1} \cdot$ Toshiaki Sunazuka $^{2} \cdot$ Naoko Sueoka-Aragane $^{1}$
}

Received: 15 August 2019 / Revised: 22 November 2019 / Accepted: 3 December 2019 / Published online: 9 December 2019

(c) The Author(s) 2019

\begin{abstract}
Objective Macrolides have been reported to reduce the exacerbation of severe asthma. The aim of this study was to clarify the effects and mechanisms of EM900, a non-antibiotic macrolide, on allergic airway inflammation.

Methods Mice were sensitized and challenged by house dust mite (HDM), then exposed to polyinosinic-polycytidylic acid (poly(I:C)) as a model of asthma complicated with viral infection. Mice were administered with EM900. Airway inflammation was assessed from inflammatory cells in bronchoalveolar lavage fluid (BALF) and cytokines in lung tissues. Lung interstitial macrophages were counted by flow cytometry. Cytokine production, phosphorylation of NF- $\kappa B$, and p38 in macrophages were examined by ELISA and western blotting.

Results Counts of cells in BALF and concentrations of IL-13, IL-5, RANTES, IL-17A, and MIP-2 were significantly decreased by EM900 compared to those without EM900. Percentages of lung interstitial macrophages were significantly decreased with EM900. Concentrations of IL-6, RANTES, and MIP-2 induced by HDM and poly(I:C) were significantly suppressed by EM900 through the suppression of NF-kB and p38 phosphorylation in macrophages.

Conclusions HDM and poly(I:C)-induced airway inflammation is attenuated by EM900 with the inhibition of lung interstitial macrophages. Clinical use of EM900 is expected, because EM900 has inhibitory effects against airway inflammation without inducing bacterial drug resistance.
\end{abstract}

Keywords Asthma $\cdot \mathrm{EM} 900 \cdot \mathrm{HDM} \cdot$ Macrolide $\cdot$ Macrophage

\section{Introduction}

Asthma is an airway inflammatory disease characterized by airway hyperresponsiveness (AHR) [1]. Eosinophilic airway inflammation is induced by sensitization and exposure to allergens such as house dust mite (HDM) [2]. Type 2 cytokines, interleukin (IL)-4, IL-5, and IL-13, are mainly involved in patients with asthma [3]. Inhaled corticosteroid (ICS) has contributed to disease control and reduction of mortality in recent decades [4]. However, exacerbation of asthma is frequently observed in patients with not only severe asthma, but also mild or controlled asthma. The most common cause of asthma exacerbation is respiratory infection, particularly viral infection.

Treatments for asthma have mainly been developed to address type 2 inflammation and eosinophilic inflammation. Recently, immunotherapies such as anti-immunoglobulin IgE, anti-IL-5, and anti-IL-4/IL-13 antibodies have become 
available for use in clinical situations [5-8]. However, molecular targeted therapies for non-type 2 inflammation have yet to be established. Macrolides that can be used clinically, such as erythromycin, clarithromycin (CAM) and azithromycin (AZM), have antibacterial effects, antiinflammatory effects, and gastrointestinal motility-enhancing effects. In particular, anti-inflammatory effects have gained attention for the control of asthma. In some studies, macrolides have been reported to achieve anti-inflammatory effects and reduction of the exacerbation rate of asthma, especially with the use for non-type 2 airway inflammation. CAM contributes to improved asthma control through suppression of sputum IL-8 in non-eosinophilic severe asthma [9]. AZM decreased the frequency of asthma exacerbations among patients with adult asthma with persistent symptomatic asthma experience and improved quality of life, when administered for 48 weeks in both type 2 and non-type 2 asthma [10]. However, the detailed mechanisms by which macrolides improve asthma remain unclear and long-term use of macrolides for asthma is regarded as potentially problematic in terms of inducing antibiotic resistance in bacteria. EM900 is a 12-membered non-antibiotic macrolide derived from erythromycin and has been found to exert potent antiinflammatory and immunomodulatory effects. EM900 has anti-inflammatory effects, but no antibacterial or gastrointestinal motility-enhancing effects. Given this absence of antibacterial effects, administration of EM900 carries no risk of inducing drug-resistant bacteria [11].

We have reported that monocytes recruited into the lungs represent cell sources of IL-33 in HDM-induced airway inflammation in mice [12]. Macrophage dysfunction is highly prevalent in asthma and macrophages are considered likely to play major roles in promoting the discrete inflammatory phenotypes of asthma [13].

The present study investigated the effects and mechanisms of EM900 in a mouse model of HDM and polyinosinicpolycytidylic acid (poly(I:C))-induced airway inflammation, including functions of macrophages.

\section{Materials and methods}

\section{Allergens and chemicals}

HDM extracts from Dermatophagoides farinae were purchased from ITEA (Tokyo, Japan). Poly(I:C) (SigmaAldrich, St. Louis, MO), as a synthetic analog of doublestranded (ds)RNA, was dissolved in phosphate-buffered saline (PBS). CAM (Tokyo Chemical Industry, Tokyo, Japan) was dissolved in dimethyl sulfoxide (DMSO) and diluted in PBS. Next, (8R,9S)-8,9-dihydro-6,9-epoxy8,9-anhydropseudoerythromycin A (EM900), provided by
Kitasato University, was dissolved in DMSO and diluted in PBS.

\section{Mice}

Six-week-old female BALB/c mice (Japan SLC, Hamamatsu, Japan) were kept at the Saga University Animal Facility under specific pathogen-free conditions. Animal experiments were undertaken in accordance with the guidelines for the care and use of experimental animals by the Japanese Association for Laboratory Animals Science (1987) and were approved by the Saga University Animal Care and Use Committee.

\section{Protocol for airway inflammation in mice}

Sensitization was achieved by intranasal administration of $25 \mu \mathrm{g}$ HDM or PBS on days 1, 8, and 15. Exposure was carried out by intranasal administration of $10 \mu \mathrm{g}$ HDM or PBS on days 22,23 , and 24 . Mice were subsequently exposed by intranasal administration of $75 \mu \mathrm{g}$ poly(I:C) or PBS on days 25 and 26 as the model of asthma complicated with viral infection. Mice were orally administered with placebo (PBS containing DMSO), $50 \mathrm{mg} / \mathrm{kg}$ CAM, or $25 \mathrm{mg} / \mathrm{kg}$ EM900 during exposure to poly(I:C) for 4 days (days 24, 25, 26, and 27). Placebo, CAM, or EM900 was administered after PBS or HDM administration on day 24, before $2 \mathrm{~h}$ of PBS or poly(I:C) administration on days 25 and 26 and before $2 \mathrm{~h}$ of collection of specimens on day 27 . We used CAM, a representative macrolide, as a control to evaluate the antiinflammatory effect of EM900. Finally, mice were divided into four groups: PBS-PBS-placebo (control group); HDMpoly(I:C)-placebo (HP group); HDM-poly(I:C)-CAM (CAM group); and HDM-poly(I:C)-EM900 (EM900 group). For all these models, mice were euthanized by intraperitoneal injection of midazolam, medetomidine, and butorphanol $24 \mathrm{~h}$ after the final poly(I:C) exposure on day 27. Bronchoalveolar lavage fluid (BALF) and lung tissues were collected for further analyses.

\section{Collection of BALF}

BALF samples were collected as described previously [14]. Briefly, a 23-G tube was inserted into the trachea, followed by two lung lavages, each with $1 \mathrm{ml}$ of saline. The cell suspension was centrifuged at $100 \times g$ for $5 \mathrm{~min}$ at $4{ }^{\circ} \mathrm{C}$. The total number of cells was counted using a hemocytometer. Cytospin samples were prepared from the cell suspension. Cell differentiation was determined by counting at least 300 leukocytes in samples stained with Diff-Quik (Siemens, Munich, Germany). 


\section{Histological examination of lung sections}

Histological examinations were performed as previously reported [12]. Lungs were fixed in 10\% neutral-buffered formalin (Wako, Osaka, Japan) and embedded in paraffin. Lung sections were stained with hematoxylin and eosin (HE) and periodic acid schiff (PAS). Slides were examined in a blinded fashion by three experienced observers, as previously described $[15,16]$. For each slide, ten randomly chosen areas were scored. Peribronchial and perivascular inflammation was scored in a semiquantitative fashion on HE slides. Mucus deposition was scored in a semiquantitative fashion on PAS slides. Scoring was as follows: $0=$ none; $1=$ minimal $; 2=$ slight $3=$ moderate; and $4=$ severe.

\section{Preparation of lung homogenates}

After BAL, the right lung was isolated and homogenized in $50 \mathrm{mM}$ Tris-buffered saline ( $\mathrm{pH}$ 7.4) containing 1.0\% Triton $\mathrm{X}-100,0.1 \%$ sodium dodecyl sulfate, $150 \mathrm{mM}$ sodium chloride, $0.5 \%$ sodium deoxycholate, $1 \mathrm{mM}$ phenylmethylsulfonyl fluoride, $1 \mu \mathrm{g} / \mathrm{ml}$ aprotinin, $1 \mu \mathrm{g} / \mathrm{ml}$ leupeptin, and $1 \mathrm{mM}$ $\mathrm{Na}_{3} \mathrm{VO}_{4}$. Lung homogenates were centrifuged at $10,000 \times g$ for $15 \mathrm{~min}$, then supernatants were collected and stored at $-80{ }^{\circ} \mathrm{C}$ until needed [14].

\section{AHR to methacholine}

Mice were anesthetized with pentobarbital and xylazine before insertion into the exposed trachea of an 18-G metal needle connected to a flexiVent system (SCIREQ, Montreal, Canada) to apply the forced oscillation technique. Next, lungs were inflated to a pressure of $30 \mathrm{cmH}_{2} \mathrm{O}$, and baseline recordings were obtained using a single frequency (2.5 Hz, $1.2 \mathrm{~s}$; Snapshot-150) and a broadband low frequency (1-20.5 Hz, $3 \mathrm{~s}$; Quick-Prime-3). Mice were then exposed to an aerosol of saline. All parameters calculated from both test signals were recorded alternately every $10 \mathrm{~s}$ for $3 \mathrm{~min}$. Finally, two deep lung inflations were administered. The above protocol was repeated five more times with aerosols containing sequentially increasing concentrations of $0.1,1.0,10,20$, and $50 \mathrm{mg} / \mathrm{ml}$ methacholine (Sigma-Aldrich Corp., St. Louis, IL).

\section{Isolation of single cells from lung tissue}

Lung tissue was cut into small pieces then transferred through a $70-\mu \mathrm{m}$ mesh before processing in a digestion buffer that included $0.02 \mathrm{mg} / \mathrm{ml}$ deoxyribonuclease I (Invitrogen, Waltham, MA) and $0.7 \mathrm{mg} / \mathrm{ml}$ collagenase type 2 (Worthington, Lakewood, NJ). The remaining red cells were lysed using BD Pharm Lysis (BD Biosciences, San Jose, CA) to obtain single-cell suspensions [12].

\section{Flow cytometry}

Single-cell suspensions were pre-incubated with $\mathrm{Fc} \gamma \mathrm{R}$ specific blocking antibody and washed before staining. Cells were stained with CD45 (clone: 30-F11), CD11c (clone: N418), CD11b (clone: M1/70), and Ly6c (clone: HK1.4) (eBioscience, San Diego, CA) before collection on a flow cytometer (FACS Verse; BD Bioscience, Franklin Lakes, NJ) and analysis using FlowJo 8.3.3 software (Tree Star, Ashland, OR).

\section{Cell culture of MH-S and peritoneal macrophages (PEC)}

The MH-S alveolar macrophage cell line was purchased from Public Health England (Porton Down, UK). MH-S was grown in RPMI 1640 medium containing 10\% fetal calf serum. To obtain PEC, mice were injected intraperitoneally with $2 \mathrm{ml}$ thioglycollate (3\%) [17]. After 4 days, peritoneal fluid was obtained by lavage with $10 \mathrm{ml}$ PBS. The fluid was centrifuged to isolate peritoneal macrophages, which were resuspended in RPMI 1640 medium. These cells were cultured at a density of $1 \times 10^{6}$ cells in RPMI 1640 containing fetal calf serum and were stimulated. These macrophages were analyzed by enzyme-linked immunosorbent assay (ELISA) and western blotting.

\section{Quantification of cytokines using ELISA}

IL-13, IL-5, regulated on activation, normal T cell expressed and secreted (RANTES), IL-17A, macrophage inflammatory protein 2 (MIP-2), IL-1 $\beta$ and monocyte chemoattractant protein-1 (MCP-1) were measured from lung homogenates using ELISA kits (R\&D Systems, Minneapolis, MN), according to the instructions from the manufacturers. MH-S and PEC were stimulated with HDM and poly(I:C) and various concentrations of CAM or EM900 were added. After $24 \mathrm{~h}$ of stimulation, MCP-1, IL-6, RANTES, and MIP-2 were measured from culture supernatants using ELISA.

\section{Western blotting in MH-S and PEC}

MH-S and PEC were stimulated with HDM and poly(I:C) and CAM or EM900 was added. After 60 min of stimulation, samples were washed with cold PBS buffer and lysed in lysis buffer containing 25\% LDS sample buffer (NP0007; Invitrogen) and 5\% DTT. Samples were boiled for $5 \mathrm{~min}$, then loaded on sodium dodecyl sulfate polyacrylamide gel electrophoresis (SDS-PAGE) and transferred to nitrocellulose membranes (GE Healthcare Life Sciences, Chicago, IL). Membranes were blocked with 5\% bovine serum albumin (Sigma-Aldrich Corp., St. Louis, IL). Membranes were incubated with the specific primary antibodies. After washing 
with Tris-buffered saline containing $0.1 \%$ Tween-20 (TBS$\mathrm{T})$, membranes were incubated with the secondary antibodies. After washing with TBS-T, membranes were incubated with ImmunoStar ${ }^{\circledR}$ LD containing luminescence solution or ImmunoStar ${ }^{\circledR}$ Zeta containing chemiluminescence solution (Wako). Films were scanned and protein bands were quantified using the C-DiGit ${ }^{\circledR}$ Blot Scanner (LI-COR). Antibodies of nuclear factor- $\kappa \mathrm{B}(\mathrm{NF}-\kappa \mathrm{B}) \mathrm{p} 65$, phosphorylated NF- $\kappa \mathrm{B}$ p65, p38, and phosphorylated p38 were purchased from Cell Signaling Technology (Danvers, MA) [18].

\section{Statistical analysis}

Analysis of variance (ANOVA) was used for multiple comparisons of continuous variables. When a significant difference was identified, the difference between each group was tested using non-parametric Mann-Whitney $U$ test. All tests were two-sided and significance was set at the level of $p<0.05$. Data were analyzed using JMP Pro version 14 (SAS Institute Japan, Tokyo, Japan).

\section{Results}

\section{EM900 suppressed HDM and poly(I:C)-induced airway inflammation}

We investigated the anti-inflammatory effects of CAM and EM900 in a mouse model of HDM and poly(I:C)-induced airway inflammation. Numbers of total cells, neutrophils, lymphocytes, and eosinophils in BALF were all significantly increased by HDM and poly(I:C) and were significantly suppressed by CAM or EM900 administrations. Numbers of macrophages were not suppressed by CAM or EM900 administrations. There was no significant difference between CAM and EM900 groups (Fig. 1a). On pathologic examination of the lungs, intense infiltration of inflammatory cell and marked mucus deposition were seen in the HP group and were significantly attenuated in the CAM and EM900 groups (Fig. 1b, c).

\section{EM900 suppressed both type 2 and non-type 2 airway inflammation}

Levels of cytokines in lung tissues were measured by ELISA. Concentrations of IL-13, IL-5, RANTES, IL-17A, MIP-2, IL-1 $\beta$, and MCP-1 were significantly increased by HDM and poly(I:C) administrations and were significantly suppressed by CAM or EM900 administrations, except for RANTES, IL-1 $\beta$, and MCP-1 in the CAM group. There was no significant difference between CAM and EM900 groups (Fig. 1d-j). These results suggested that CAM and EM900 suppressed not only non-type 2 neutrophilic airway inflammation, but also type 2 eosinophilic airway inflammation.

In complementary studies, we investigated the antiinflammatory effects of CAM and EM900 in a mouse model of HDM-induced airway inflammation without poly(I:C). Numbers of total cells, neutrophils, lymphocytes and eosinophils in BALF were not suppressed or increased by CAM or EM900 administrations (Supplementary Fig. 1a). Concentrations of cytokines in lung tissues were not suppressed by CAM or EM900 administrations, except for IL-5 in the EM900 (Supplementary Fig. 1b-f). Moreover, we investigated an effect of poly(I:C) in a mouse model of HDMinduced airway inflammation. Neutrophilic airway inflammation including numbers of neutrophils in BALF and concentrations of MIP-2 in lung tissues was significantly increased by addition of poly(I:C) compared with only HDM (Supplementary Fig. 2a-f).

\section{AHR is attenuated by EM900}

Airway resistance, represented by AHR, was measured by flexiVent. Airway resistance was higher in the HP group than in the control group and was significantly lower in the CAM and EM900 group mice than in the HP group after exposure to 20 and $50 \mathrm{mg} / \mathrm{ml}$ methacholine. There was no significant difference between CAM and EM900 groups (Fig. 2) (20 mg/ml methacholine; control: $1.90 \pm 0.55 \mathrm{cmH}_{2} \mathrm{O} \cdot \mathrm{s} / \mathrm{ml}$, HP: $4.98 \pm 0.95 \mathrm{cmH}_{2} \mathrm{O} \cdot \mathrm{s} / \mathrm{ml}, \mathrm{CAM}: 3.76 \pm 0.57 \mathrm{cmH}_{2} \mathrm{O} \cdot \mathrm{s} /$ $\mathrm{ml}$, EM900: $3.36 \pm 0.38 \mathrm{cmH}_{2} \mathrm{O} \cdot \mathrm{s} / \mathrm{ml}, 50 \mathrm{mg} / \mathrm{ml}$ methacholine; control: $2.53 \pm 0.25 \mathrm{cmH}_{2} \mathrm{O} \cdot \mathrm{s} / \mathrm{ml}$, HP: $6.78 \pm 1.31 \mathrm{cmH}_{2} \mathrm{O} \cdot \mathrm{s} / \mathrm{ml}$, CAM: $4.21 \pm 0.41 \mathrm{cmH}_{2} \mathrm{O} \cdot \mathrm{s} / \mathrm{ml}$, EM900: $\left.3.81 \pm 0.22 \mathrm{cmH}_{2} \mathrm{O} \cdot \mathrm{s} / \mathrm{ml}\right)$.

\section{Recruitment of interstitial macrophages into the lungs was attenuated by EM900}

To clarify the mechanisms underlying the effects of CAM and EM900 in HDM and poly(I:C)-induced airway inflammation, we focused on the action of macrophages. To identify lung cell populations in these mice, we examined single-cell suspensions by flow cytometry. Lung resident macrophages were classified as interstitial macrophages and alveolar macrophages [19]. We defined CD $45^{+}$, $\mathrm{CD} 11 \mathrm{c}^{\text {low }}, \mathrm{CD} 11 \mathrm{~b}^{+}$, and $\mathrm{Ly} 6 \mathrm{c}^{-}$cells as lung interstitial macrophages with reference to previous reports [20, 21]. The percentage of interstitial macrophages in the lungs was significantly increased by HDM and poly(I:C) administration and was significantly decreased by CAM 


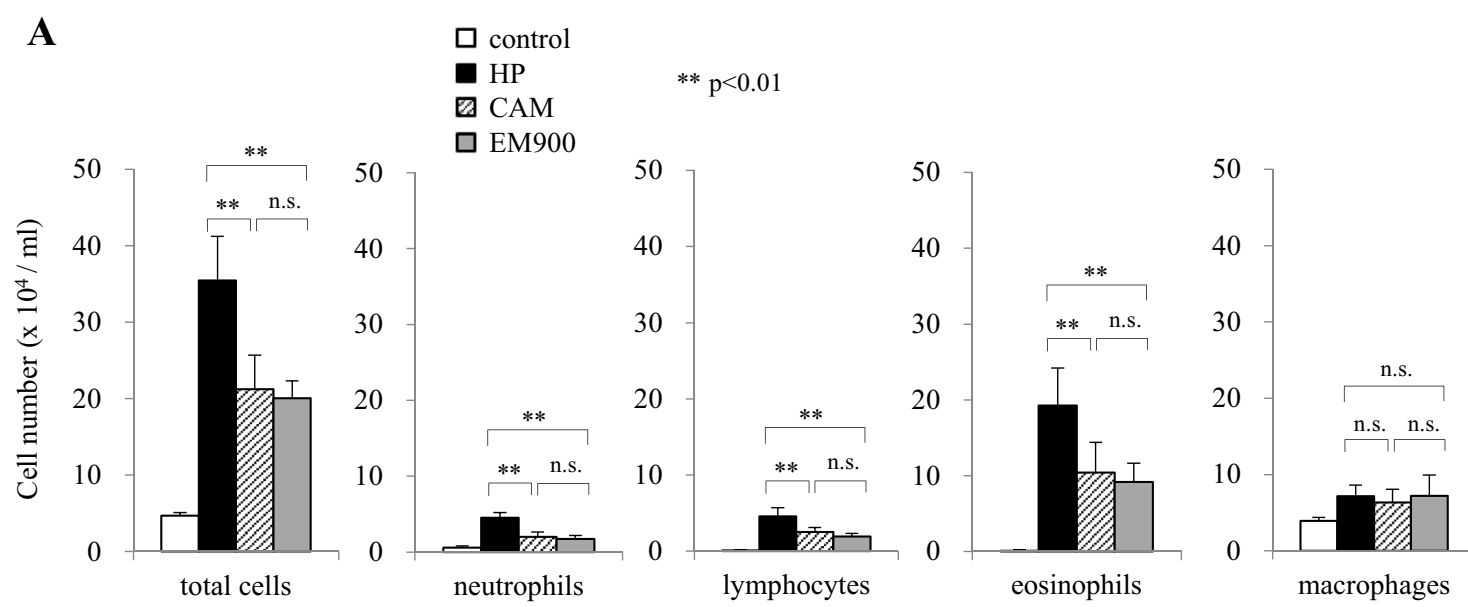

B

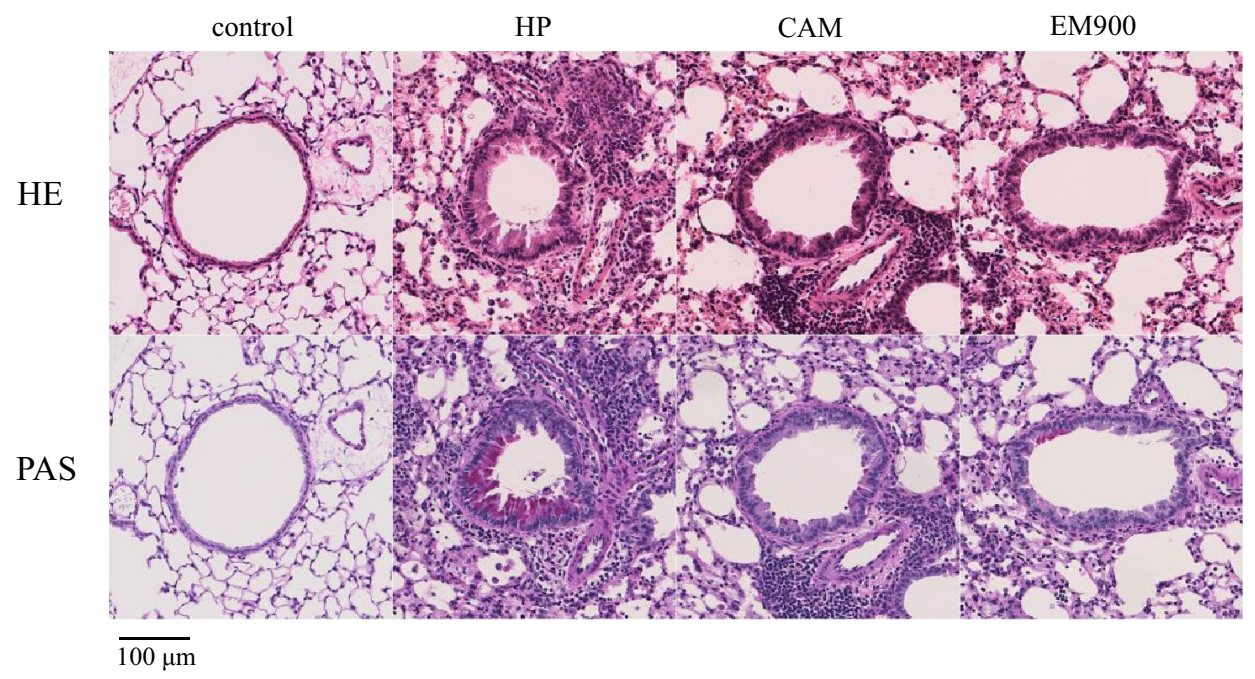

C
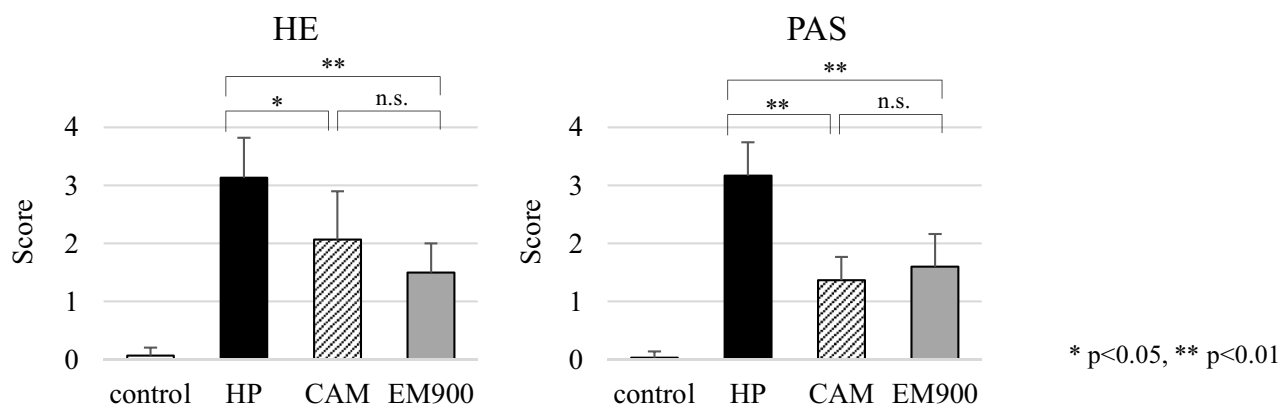

Fig. 1 CAM or EM900 suppressed HDM and poly(I:C)-induced airway inflammation. a Bronchoalveolar lavage fluid analysis for total cell counts among control, HP, CAM, and EM900 mice ( $n=6$ in each group). b Histological examination for airway inflammation. Sections were stained with hematoxylin and eosin (HE) and periodic acid schiff $(\mathrm{PAS})$. Original magnification, $\times 200$. c Slides were scored for peribronchial inflammation and numbers of mucuspositive cells, using a semiquantitative score from 0 to 4 . Histological scoring on HE and PAS stains is as follows: $0=$ none; $1=$ minimal; $2=$ slight; $3=$ moderate; or $4=$ severe. Concentrations of IL-13

(D), IL-5 (E), RANTES (F), IL-17A (G), MIP-2 (H), IL-1 $\beta$ (I) and MCP-1 (J) in lung tissues were measured by ELISA $(n=6$ in each group). Bar graphs represent mean \pm standard deviation (SD) of four independent experiments. $* p<0.05$, $* * p<0.01$, n.s. not significant, $C A M$ clarithromycin, $H D M$ house dust mite, $\operatorname{poly}(I: C)$ polyinosinicpolycytidylic acid, RANTES regulated on activation, normal $\mathrm{T}$ cell expressed and secreted, MIP-2 macrophage inflammatory protein 2, $M C P-1$ monocyte chemoattractant protein-1, ELISA enzyme-linked immunosorbent assay 

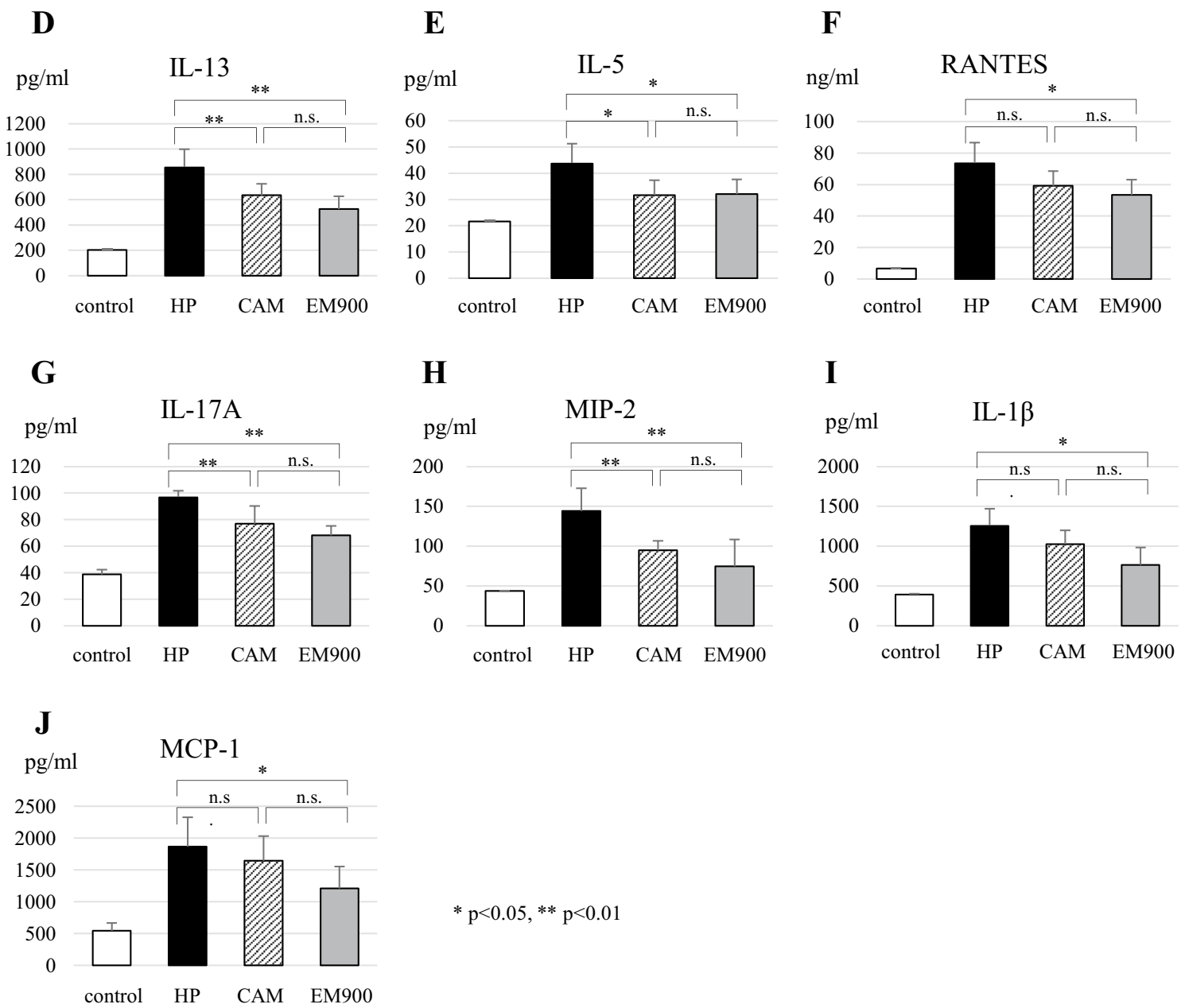

Fig. 1 (continued)

or EM900 administrations. There was no significant difference between CAM and EM900 groups (Fig. 3a, b) (control 0.19 $\pm 0.04 \%$; HP 10.14 $\pm 2.87 \%$, CAM 5.18 $\pm 3.75 \%$; EM900 $4.43 \pm 2.88 \%$ ). Furthermore, we evaluated the production of MCP-1 from macrophages using $\mathrm{MH}-\mathrm{S}$ and $\mathrm{PEC}$ in vitro. Concentrations of $\mathrm{MCP}-1$ were significantly increased by HDM and poly(I:C) stimulations and were significantly suppressed by addition of CAM or EM900 in $\mathrm{MH}-\mathrm{S}$ and PEC (Fig. 3c). These results (including Fig. 1j) suggested that CAM and EM900 attenuated the recruitment of interstitial macrophages in the lungs via suppression of MCP-1 production from macrophages.

\section{EM900 suppressed production of HDM and poly $(\mathrm{l}: \mathrm{C})$-induced proinflammatory cytokines in vitro}

To clarify the interaction between macrolides and macrophages, we used in vitro assays of macrolides and macrophages. Concentrations of IL-6, RANTES, and MIP-2 were significantly increased by HDM and poly(I:C) stimulations and were significantly suppressed by CAM or EM900 in MH-S and PEC in a dose-dependent manner (Fig. 4a-f).

\section{EM900 attenuated NF-KB and p38 signaling in vitro}

To clarify the mechanisms by which macrolides act on macrophages, we investigated cell signaling pathways in $\mathrm{MH}-\mathrm{S}$ and PEC by western blotting. Levels of phosphorylated $\mathrm{NF}-\kappa \mathrm{B}$ and phosphorylated p38-mitogen-activated protein kinase (MAPK) were significantly increased by HDM and poly(I:C) stimulations and were significantly suppressed by the addition of CAM or EM900 in MH-S and PEC (Fig. 5a-d). These results suggested that CAM and EM900 attenuated the production of proinflammatory cytokines from macrophages via the suppression of NF- $\mathrm{NB}$ and p38 signaling. 


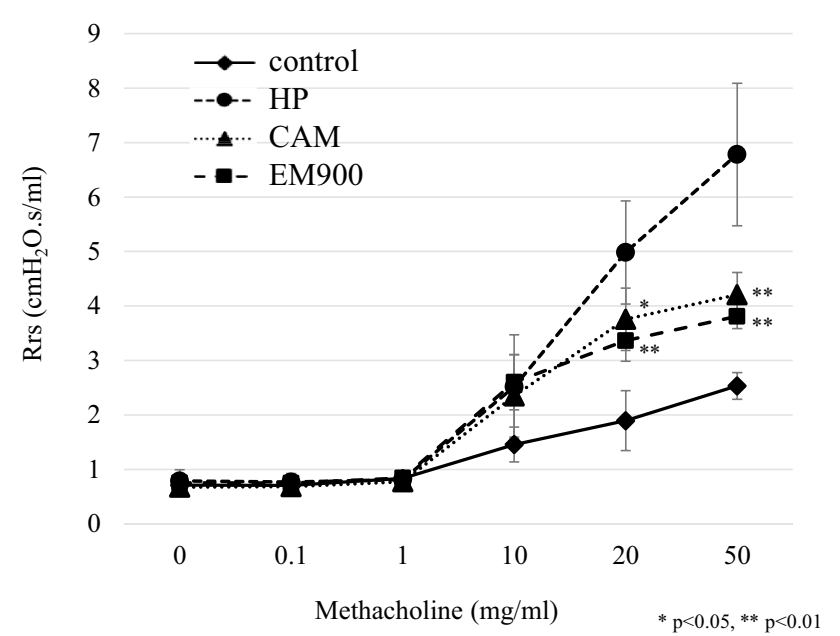

Fig. 2 Airway hyperresponsiveness was attenuated by CAM or EM900. Airway hyperresponsiveness was measured through assessment of airway resistance according to graded concentrations of methacholine in control and HP, CAM, and EM900-treated mice ( $n=6$ in each group). Graphs represent mean \pm standard deviation (SD) of four independent experiments. $* p<0.05$, ** ${ }^{*}<0.01$ (compared with HP group). CAM clarithromycin

\section{Discussion}

The present study demonstrated that the non-antibiotic macrolide EM900 attenuated HDM and poly(I:C)-induced airway inflammation with inhibition of macrophage recruitment and activation in a mouse model. EM900 decreased the number of eosinophils and neutrophils in BALF and inflammatory cells infiltration and mucus deposition in histological lung specimens and decreased production of cytokines, including IL-13, IL-5, RANTES, IL-17A, MIP-2, and IL-1 $\beta$. IL-13, IL-5, and RANTES are mainly involved in type 2 eosinophilic airway inflammation and IL-17A, MIP-2, and IL-1 $\beta$ are mainly involved in non-type 2 neutrophilic airway inflammation. These results suggested that EM900 suppressed both type 2 and non-type 2 airway inflammation. To the best of our knowledge, this is the first report to demonstrate the effect of the non-antibiotic macrolide EM900 in HDM and poly(I:C)-induced airway inflammation in mice and to examine the mechanisms of action through lung interstitial macrophages.

Macrolides have been considered effective for antiinflammatory effects and have reduced the exacerbation rate in severe asthma. The following findings have been shown in animal models. CAM attenuates airway inflammation via $\mathrm{TNF} \alpha$ and IL-17A suppression in a mouse model of steroidresistant asthma [22]. AZM attenuates ovalbumin (OVA)induced airway inflammation in a mouse model [23]. AZM ameliorates OVA and lipopolysaccharide (LPS)-induced airway inflammation, both type 2 and non-type 2 , in a mouse model [24]. The following findings have been shown in clinical studies. CAM contributes to improved asthma control through suppression of sputum IL-8 in non-eosinophilic severe asthma [9]. AZM decreased the frequency of asthma exacerbations in patients with adult asthma with persistent symptomatic asthma experience and improved quality of life [10]. This study showed that AZM is effective against both type 2 dominant and non-type 2 dominant asthma, but the mechanisms underlying these effects are not yet fully understood. The present study showed that EM900 or CAM suppressed both type 2 and non-type 2 inflammation. We consider that these results are because EM900 or CAM suppressed both RANTES and MIP-2, which are involved in eosinophil and neutrophil migration, respectively $[25,26]$.

We have shown that EM900 or CAM decreased not only the number of neutrophils, but also the number of eosinophils in an HDM and poly(I:C)-induced airway inflammation model. We considered three mechanisms by which EM900 or CAM could reduce eosinophils: reduction of RANTES; interaction between eosinophils and neutrophils; and relationship between macrophages and CD4 T-cells. First, the decline in eosinophils is attributed to decreased production of RANTES. RANTES is also known as CCL5, a C-C chemokine and has been reported as an eosinophil-attracting chemokine in airway inflammation. Eosinophil recruitment following allergen challenge is associated with the release of the chemokine RANTES into asthmatic airways [25]. In this study, RANTES were decreased by EM900 or CAM both in vivo and in vitro, which might be related to decreases in eosinophils. Second, inhibition of neutrophils may lead to inhibition of eosinophils. A previous study showed that the combination of neutrophils and LPS led eosinophils to accumulate in the airways [27]. In this study, neutrophils were suppressed by EM900 or CAM in BALF, which might be related to decreases in eosinophils. Finally, macrophages may be involved in CD4 T-cells through IL-6 production. Another study showed that alveolar macrophages from atopic asthmatics enhanced IL-5 production by allergenspecific CD4 T-cells due to their production of IL-6 [28]. EM900 could potentially have inhibited IL-5 through suppression of IL- 6 production from macrophages and suppressed eosinophilic airway inflammation.

Long-term use of antibiotics is a problem in terms of inducing drug resistance in bacteria or mycobacteria [29]. Previous studies have shown that total antibiotic use correlates with penicillin-non-susceptible Streptococcus pneumoniae and macrolide-resistant $S$. pneumoniae in various countries [30]. Four years after treatment, high levels of the macrolide resistance gene ermB were still evident, indicating that antibiotic resistance, once selected for, can persist for 


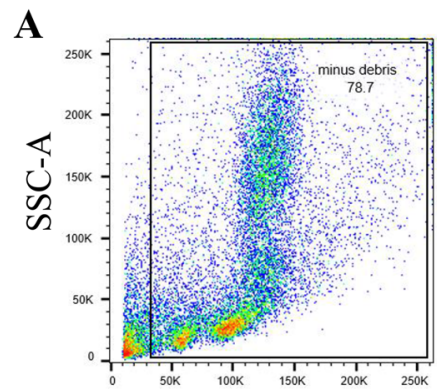

FSC-A

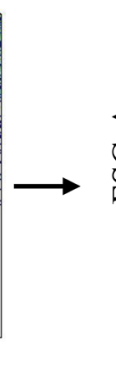

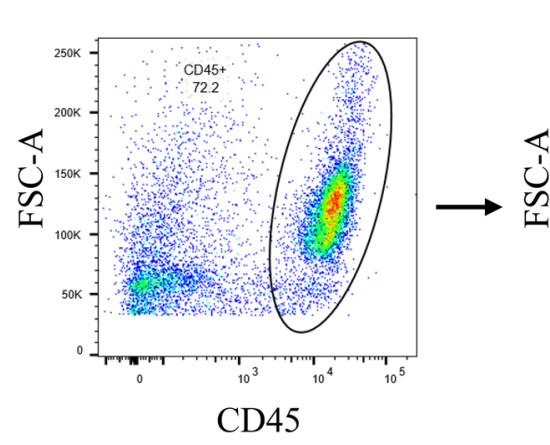

CD45

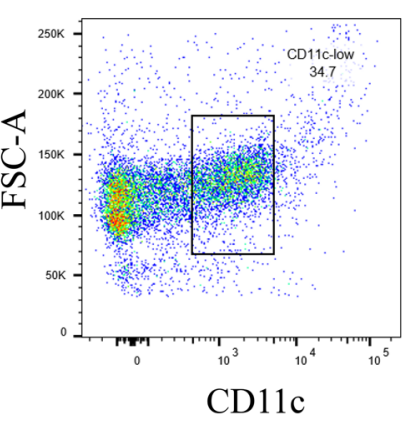

CD11c
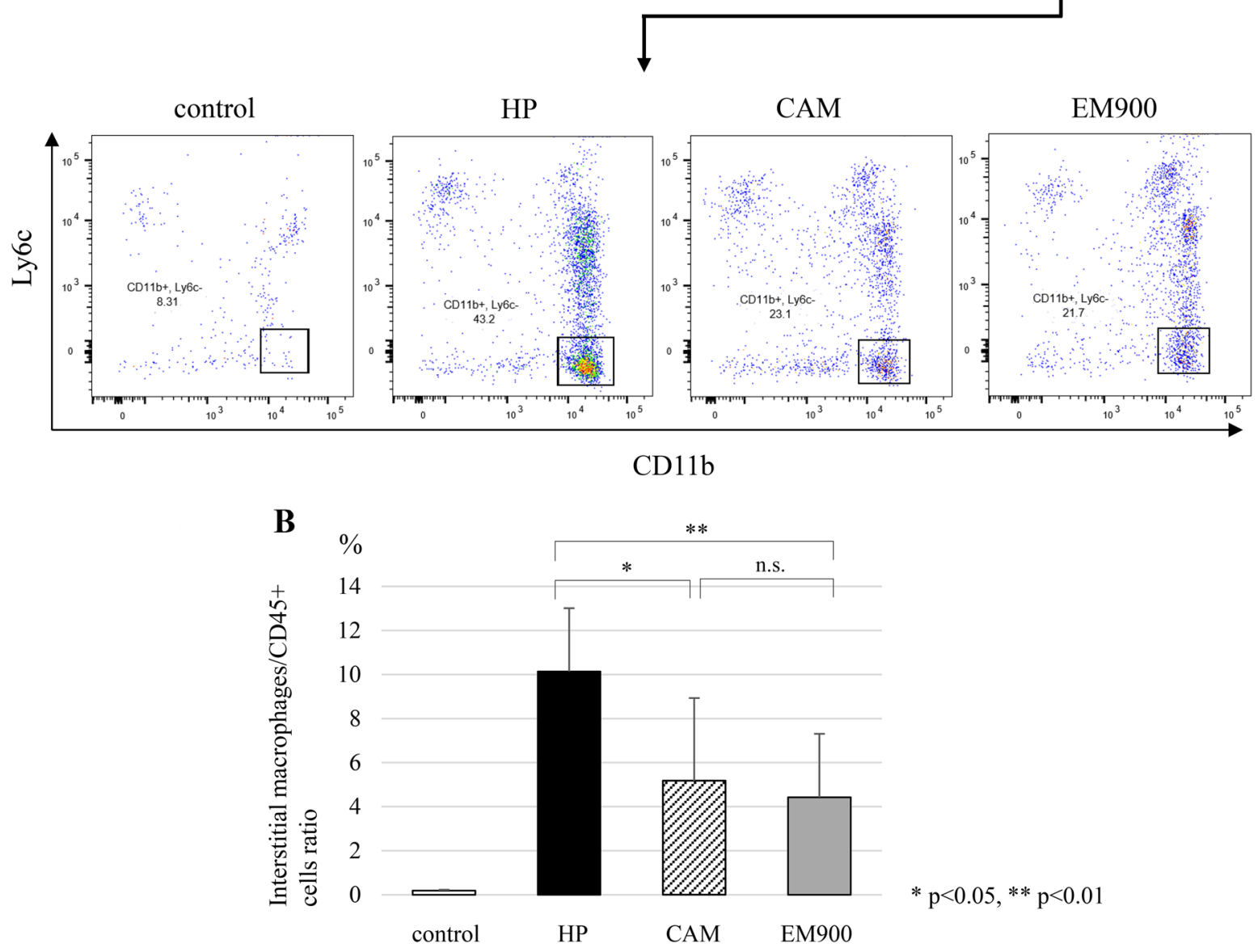

C

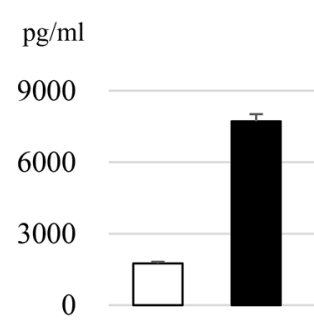

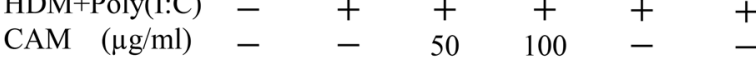

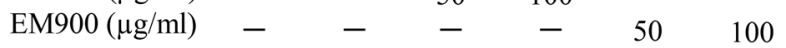

MCP-1 (PEC)

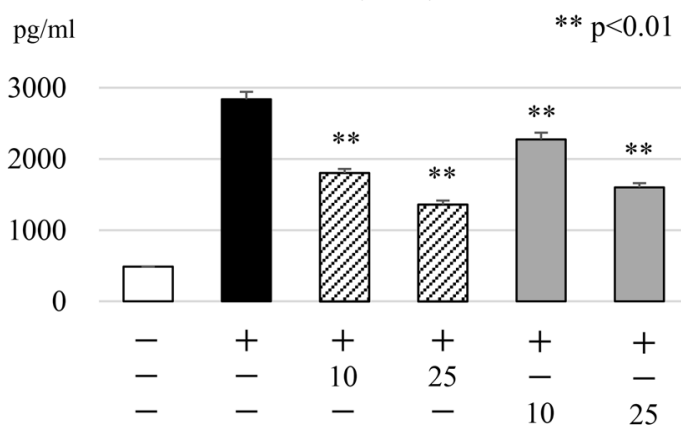


4Fig. 3 CAM or EM900 decreased numbers of lung macrophages. a Cells identified from digested lungs after exclusion of doublets and debris, leukocytes are separated by CD45 staining. CD11c-low, CD11b-positive, and Ly6c-negative cells are defined as interstitial macrophages. b Percentages of $\mathrm{CD}_{4} 5^{+}, \mathrm{CD} 11 \mathrm{c}^{\text {low }}, \mathrm{CD}_{1} 1 \mathrm{~b}^{+}$, and Ly $6 \mathrm{c}^{-}$cells in control and HP, CAM, and EM900-treated mice $(n=6$ in each group). Bar graphs represent mean \pm standard deviation (SD) of four independent experiments. ${ }^{*} p<0.05, * * p<0.01$, n.s. not significant. c Concentration of MCP-1 in the supernatant of MH-S or PEC that are stimulated with HDM and poly(I:C) for $24 \mathrm{~h}$. Bar graphs represent mean \pm standard deviation (SD) of independent experiments. ${ }^{* *} p<0.01$ (compared with $\mathrm{HDM}+$ poly(I:C) without CAM and EM900). CAM clarithromycin, $M C P-1$ monocyte chemoattractant protein-1, $P E C$ peritoneal macrophages, $H D M$ house dust mite, $\operatorname{poly}(I: C)$ polyinosinic-polycytidylic acid

longer than previously recognized [31]. Even with administration of CAM for a period of time as short as 7 days, resistant streptococci in the pharynx after 180 days were increased [32]. A few studies have shown the effects of non-antibiotic macrolides. GS-459755 and GS-560660 improved phagocytosis of macrophages in vitro and GS-459755 improved mucus clearance in human bronchial epithelial cells $[33,34]$. EM900 is also a non-antibiotic macrolide that only shows anti-inflammatory effects [11]. A previous study showed that EM900 administration inhibited LPS-induced mucus production from rat nasal epithelium and inhibited the MUC5AC secretion induced by TNF $\alpha$ from human airway epithelial cells [35]. EM900 inhibits invasive pneumococcal infections by accelerating the clearance of pneumococcal nasopharyngeal colonization in mice [36]. EM900 is therefore considered to attenuate airway inflammation without inducing drug-resistant bacteria. The present report is the first to show the effects of the non-antibiotic macrolide for allergic airway inflammation.

The most common cause of asthma exacerbation is viral infection, at 76-80\% [37]. Rhinovirus, respiratory syncytial virus, and influenza virus have been reported to be involved in asthma exacerbation [38, 39]. Genomic single-stranded RNA is converted to dsRNA in the infected cells. Virusderived dsRNA induces inflammatory cytokine production in the respiratory tract of asthma patients and eosinophils and neutrophils accumulate in the respiratory tract, causing asthma exacerbation [40]. Several studies have used antigen (HDM or OVA) and poly(I:C) in virus-induced asthma exacerbation models in mice [41-44]. The present study therefore examined HDM and poly(I:C) administrations to mimic virus-induced asthma exacerbation. A previous study showed that EM900 was able to suppress IL-6 and IL- $1 \beta$ production in human tracheal epithelial cells after stimulation with rhinovirus RV14 [45]. EM900 induced a positive survival effect in influenza $A$ virus infected mice [46]. These findings showed that EM900 can exert antiviral activity. EM900 also proved effective in the present study, and thus can be effective against virus-induced asthma exacerbation. Moreover, the finding that EM900 affects macrophages along with bronchial epithelial cells represents a novel insight.

We have previously shown mechanisms underlying the involvement of monocytes or macrophages in HDMinduced airway inflammation. IL-33 from monocytes recruited to the lung contributes to the pathogenesis of HDM-induced airway inflammation [12]. Saturated fatty acids increase the recruitment of lung macrophages and augments HDM-induced airway inflammation in obese mice [47]. In the present study, the number of interstitial macrophages (defined as $\mathrm{CD}^{+} 5^{+}, \mathrm{CD} 11 \mathrm{c}^{\text {low }}, \mathrm{CD} 11 \mathrm{~b}^{+}$, and Ly $6 \mathrm{c}^{-}$cells) was significantly decreased with EM900 or CAM treatment in HDM and poly(I:C)-induced airway inflammation in mice. Lung macrophages in asthma play roles in allergen recognition and production of inflammatory cytokines [48]. A recent study supports the notion that interstitial macrophages play a role in immune responses, including infection and allergic airway inflammation [20].

Cytokine concentrations of IL-6, RANTES, and MIP-2 induced by HDM and poly(I:C) were significantly suppressed by EM900 or CAM in vitro. Furthermore, activation of NF-kB and p38 was inhibited by EM900 or CAM treatment with HDM and poly(I:C) stimulation in macrophages. These data suggested that EM900 treatment directly affected macrophages through NF- $\mathrm{KB}$ and $\mathrm{p} 38$ in HDM and poly(I:C)-induced cytokine production. A previous study showed that $\mathrm{p} 38$-MAPK was associated with steroid resistance among patients with asthma [49]. Alveolar macrophages derived from asthmatic patients showed higher p38 activation in severe asthma than in mild asthma [49]. Production of IL- 6 and IL- $1 \beta$ from alveolar macrophages was suppressed by administration of p38 inhibitor in combination with dexamethasone [50]. NF- $\mathrm{KB}$ activation is also reportedly associated with production of RANTES and IL-8 from peripheral blood mononuclear cells in patients with severe asthma [51]. NF- $\mathrm{KB}$ and $\mathrm{p} 38$ are involved in severe asthma or steroid resistance and control of these pathways is important.

In conclusion, HDM and poly(I:C)-induced airway inflammation is attenuated by EM900 via suppression of both type 2 and non-type 2 cytokines. Cytokine 
A

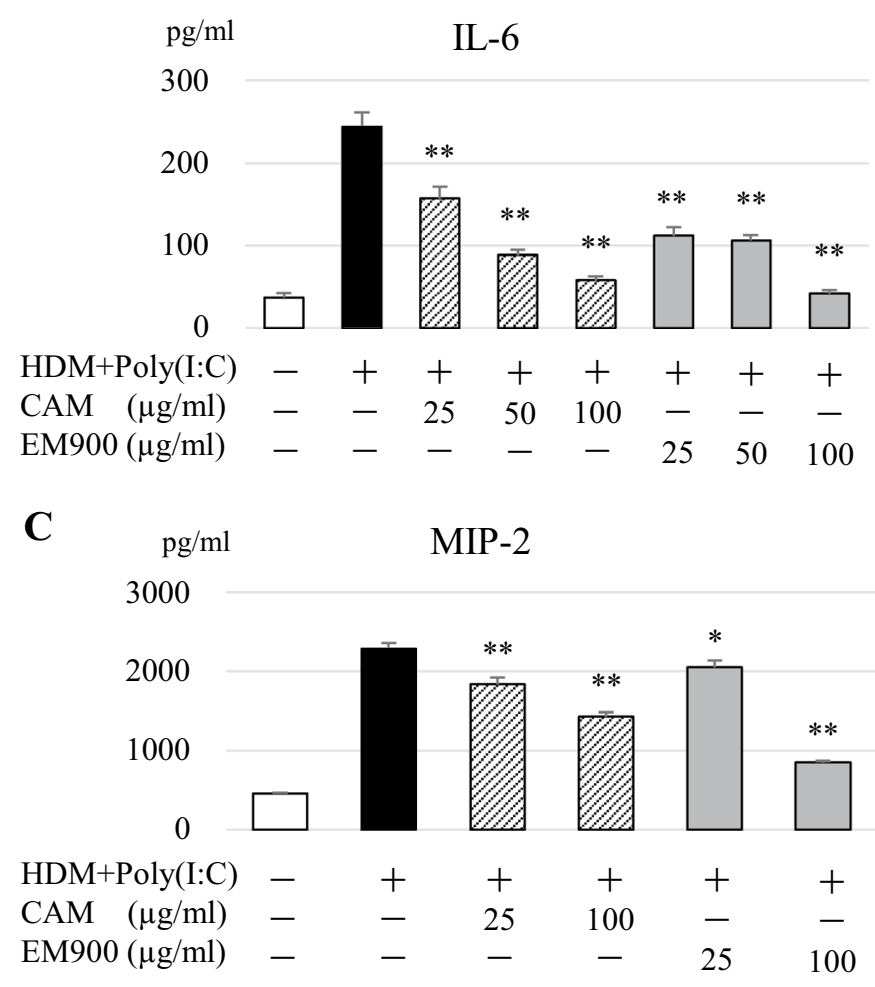

D

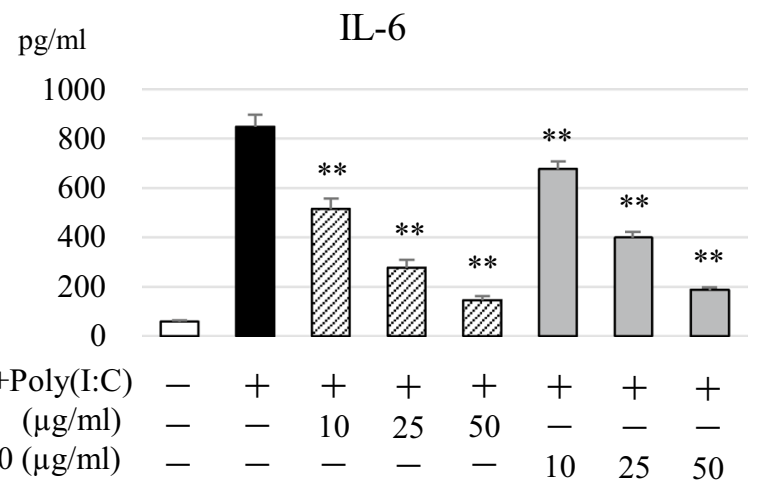

F

$\mathrm{pg} / \mathrm{ml}$

MIP-2

6000

4000

2000

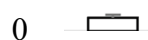
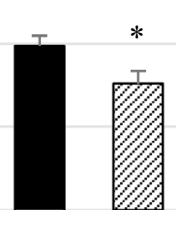

$\mathrm{HDM}+\mathrm{Poly}(\mathrm{I}: \mathrm{C}) \quad-\quad+\quad+$

$+\quad+\quad+$

$\begin{array}{lllllll}\operatorname{EM} 900(\mu \mathrm{g} / \mathrm{ml}) & - & - & - & - & 25 & 100\end{array}$
B

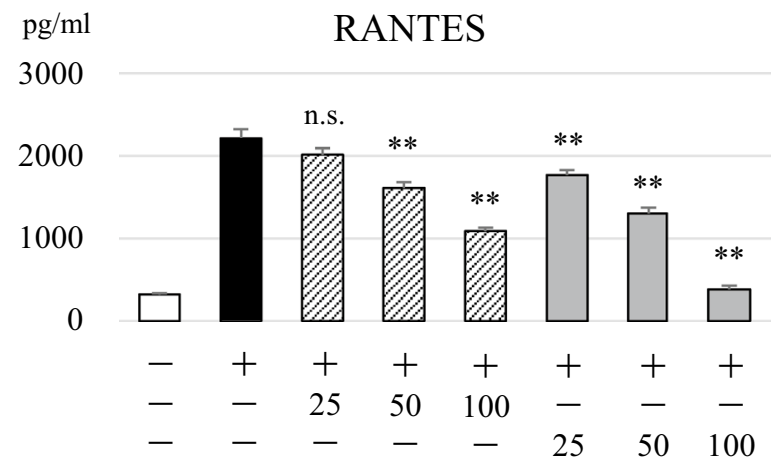

$\mathbf{E}$

$\mathrm{pg} / \mathrm{ml}$

6000

4000

2000

0

$$
\begin{array}{cccccccc}
- & + & + & + & + & + & + & + \\
- & - & 10 & 25 & 50 & - & - & - \\
- & - & - & - & - & 10 & 25 & 50
\end{array}
$$


4Fig. 4 CAM or EM900 suppressed cytokine production in macrophages. Concentrations of IL-6 (a), RANTES (b), and MIP-2 (c) in supernatant from MH-S stimulated with HDM and poly(I:C) for $24 \mathrm{~h}$. Concentrations of IL-6 (d), RANTES (e), and MIP-2 (f) of supernatant from PEC stimulated with HDM and poly(I:C) for $24 \mathrm{~h}$. Bar graphs represent mean \pm standard deviation (SD) of independent experiments. ${ }^{*} p<0.05, * * p<0.01$, n.s. not significant, (compared with $\mathrm{HDM}+$ poly(I:C) without CAM and EM900). CAM clarithromycin, RANTES regulated on activation, normal $\mathrm{T}$ cell expressed and secreted, $M I P$-2 macrophage inflammatory protein 2, HDM house dust mite, $\operatorname{poly}(I: C)$ polyinosinic-polycytidylic acid, $P E C$ peritoneal macrophages

A

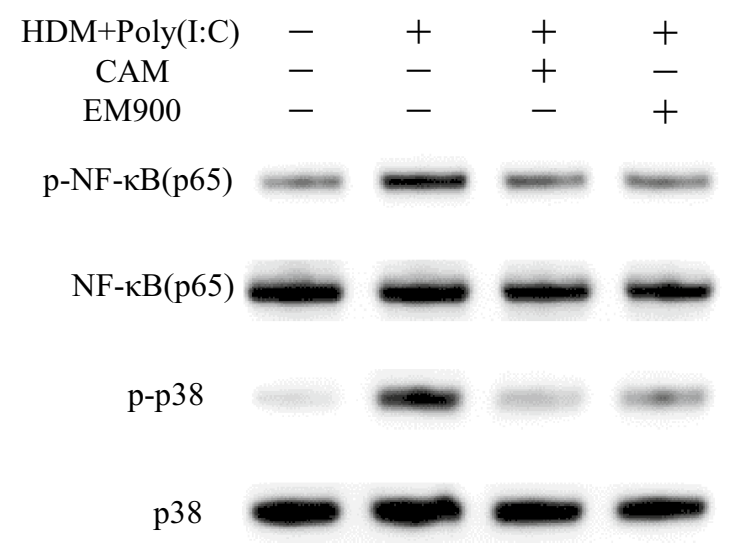

C

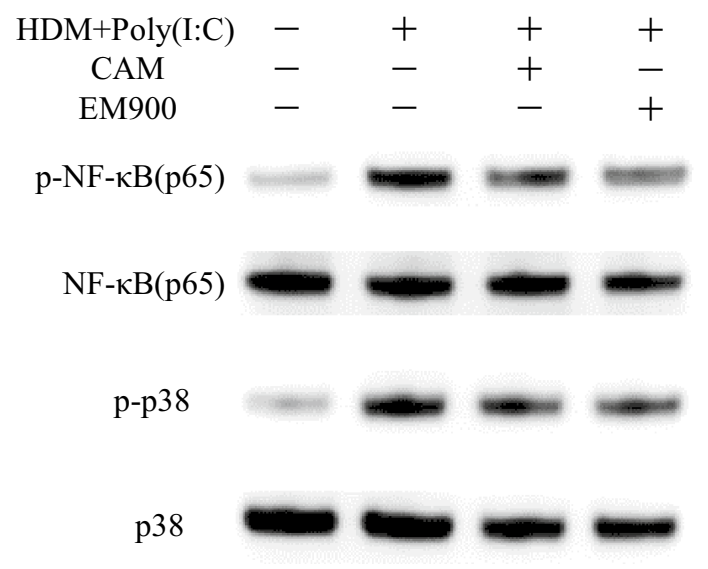

Fig. 5 CAM or EM900 attenuated NF- $\mathrm{kB}$ and p38 signaling pathways in macrophages. a MH-S stimulated with $5 \mu \mathrm{g} / \mathrm{ml} \mathrm{HDM}$ and $10 \mu \mathrm{g} / \mathrm{ml}$ poly(I:C) with or without $50 \mathrm{mg} / \mathrm{ml} \mathrm{CAM} \mathrm{or} 50 \mathrm{mg} / \mathrm{ml}$ EM900 for $60 \mathrm{~min}$. After stimulation, cells were lysed and boiled for SDS-PAGE analysis. Transferred proteins were detected by anti-phosphorylated and total NF- $\mathrm{KB}$ (p65) or anti-phosphorylated and total p38 antibodies. b Protein bands quantified by densitometric analysis. c PEC stimulated with $5 \mu \mathrm{g} / \mathrm{ml} \mathrm{HDM}$ and $10 \mu \mathrm{g} / \mathrm{ml}$ poly(I:C) with or without $50 \mathrm{mg} / \mathrm{ml} \mathrm{CAM}$ or $50 \mathrm{mg} / \mathrm{ml} \mathrm{EM} 900$ for $60 \mathrm{~min}$. After productions are suppressed by EM900 with inhibition of lung interstitial macrophages. Clinical use of EM900 is anticipated, because EM900 has inhibitory effects on airway inflammation equivalent to those of CAM and does not induce drug resistance to bacteria.

B
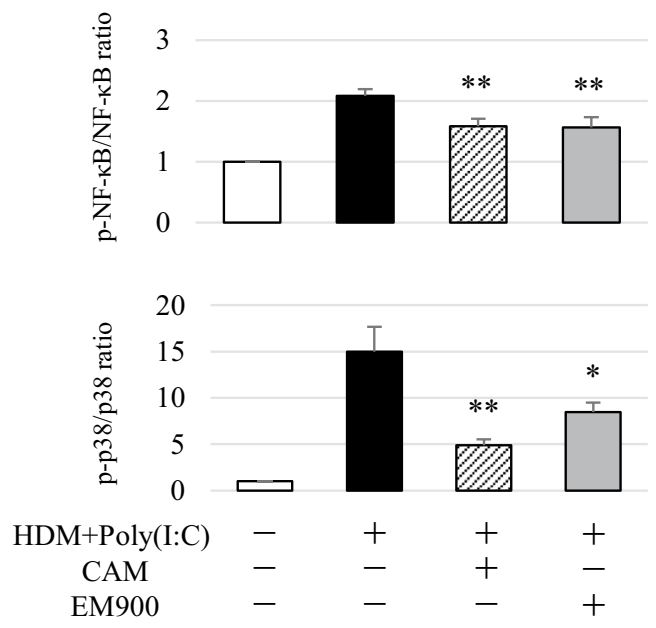

D
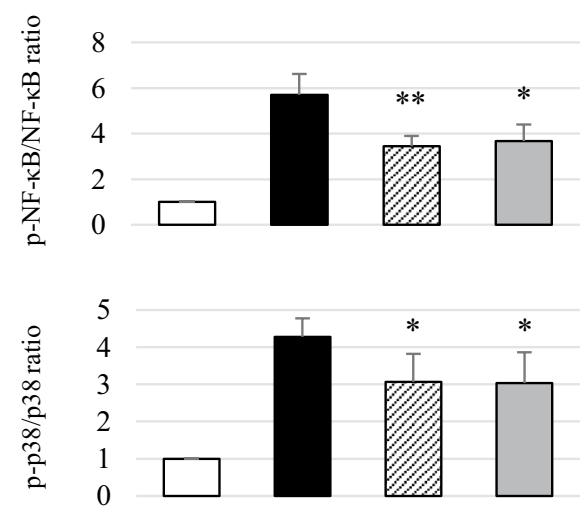

$$
\begin{array}{lllll}
\mathrm{HDM}+\text { Poly(I:C) } & - & + & + & + \\
\text { CAM } & - & - & + & - \\
\text { EM900 } & - & - & - & + \\
& & & \\
& & & * \mathrm{p}<0.05,{ }^{* *} & \mathrm{p}<0.01
\end{array}
$$

stimulation, cells were lysed and boiled for SDS-PAGE analysis. Transferred proteins were detected by anti-phosphorylated and total NF- $\mathrm{kB}$ (p65) or anti-phosphorylated and total p38 antibodies. d Protein bands quantified by densitometric analysis. Bar graphs represent mean \pm standard deviation (SD) of independent experiments. $* p<0.05, * * p<0.01$ (compared with HDM + poly(I:C) without CAM and EM900). CAM clarithromycin, $H D M$ house dust mite, poly(I:C) polyinosinic-polycytidylic acid, $P E C$ peritoneal macrophages 
Acknowledgements This study was supported by the Researcher Supporting Program of Saga University (KT).

Author contributions HS, HT, GK, and KT designed and performed the study. KK contributed to production of HDM. YN, SŌ, and TS developed and provided EM900. NSA and SK supervised the study. HS and KT drafted the manuscript. All authors read and approved the final manuscript.

\section{Compliance with ethical standards}

Conflict of interest All authors declare that there are no conflicts of interest regarding the publication of this paper.

Open Access This article is licensed under a Creative Commons Attribution 4.0 International License, which permits use, sharing, adaptation, distribution and reproduction in any medium or format, as long as you give appropriate credit to the original author(s) and the source, provide a link to the Creative Commons licence, and indicate if changes were made. The images or other third party material in this article are included in the article's Creative Commons licence, unless indicated otherwise in a credit line to the material. If material is not included in the article's Creative Commons licence and your intended use is not permitted by statutory regulation or exceeds the permitted use, you will need to obtain permission directly from the copyright holder. To view a copy of this licence, visit http://creativecommons.org/licenses/by/4.0/.

\section{References}

1. Papi A, Brightling C, Pedersen SE, Reddel HK. Asthma. Lancet. 2018;391(10122):783-800.

2. Calderon MA, Linneberg A, Kleine-Tebbe J, De Blay F, Hernandez Fernandez de Rojas D, Virchow JC, et al. Respiratory allergy caused by house dust mites: What do we really know? J Allergy Clin Immunol. 2015;136(1):38-48.

3. Lambrecht BN, Hammad H. The immunology of asthma. Nat Immunol. 2015;16(1):45-56.

4. Reddel HK, Bateman ED, Becker A, Boulet LP, Cruz AA, Drazen JM, et al. A summary of the new GINA strategy: a roadmap to asthma control. Eur Respir J. 2015;46(3):622-39.

5. Holgate S, Smith N, Massanari M, Jimenez P. Effects of omalizumab on markers of inflammation in patients with allergic asthma. Allergy. 2009;64(12):1728-36.

6. FitzGerald JM, Bleecker ER, Nair P, Korn S, Ohta K, Lommatzsch $\mathrm{M}$, et al. Benralizumab, an anti-interleukin-5 receptor alpha monoclonal antibody, as add-on treatment for patients with severe, uncontrolled, eosinophilic asthma (CALIMA): a randomised, double-blind, placebo-controlled phase 3 trial. Lancet. 2016;388(10056):2128-41.

7. Castro M, Corren J, Pavord ID, Maspero J, Wenzel S, Rabe KF, et al. Dupilumab efficacy and safety in moderate-to-severe uncontrolled asthma. N Engl J Med. 2018;378(26):2486-96.

8. Ortega HG, Liu MC, Pavord ID, Brusselle GG, FitzGerald JM, Chetta A, et al. Mepolizumab treatment in patients with severe eosinophilic asthma. N Engl J Med. 2014;371(13):1198-207.

9. Simpson JL, Powell H, Boyle MJ, Scott RJ, Gibson PG. Clarithromycin targets neutrophilic airway inflammation in refractory asthma. Am J Respir Crit Care Med. 2008;177(2):148-55.

10. Gibson PG, Yang IA, Upham JW, Reynolds PN, Hodge S, James $\mathrm{AL}$, et al. Effect of azithromycin on asthma exacerbations and quality of life in adults with persistent uncontrolled asthma
(AMAZES): a randomised, double-blind, placebo-controlled trial. Lancet. 2017;390(10095):659-68.

11. Sugawara A, Sueki A, Hirose T, Nagai K, Gouda H, Hirono S, et al. Novel 12-membered non-antibiotic macrolides from erythromycin A; EM900 series as novel leads for anti-inflammatory and/or immunomodulatory agents. Bioorg Med Chem Lett. 2011;21(11):3373-6.

12. Tashiro H, Takahashi K, Hayashi S, Kato G, Kurata K, Kimura $\mathrm{S}$, et al. Interleukin-33 from Monocytes Recruited to the Lung Contributes to House Dust Mite-Induced Airway Inflammation in a Mouse Model. PLoS ONE. 2016;11(6):e0157571.

13. Fricker M, Gibson PG. Macrophage dysfunction in the pathogenesis and treatment of asthma. Eur Respir J. 2017;50(3).

14. Kato G, Takahashi K, Tashiro H, Kurata K, Shirai H, Kimura S, et al. beta2 adrenergic agonist attenuates house dust mite-induced allergic airway inflammation through dendritic cells. BMC Immunol. 2014;15:39.

15. Bopp T, Dehzad N, Reuter S, Klein M, Ullrich N, Stassen M, et al. Inhibition of cAMP degradation improves regulatory $\mathrm{T}$ cellmediated suppression. J Immunol. 2009;182(7):4017-24.

16. Malinczak CA, Fonseca W, Rasky AJ, Ptaschinski C, Morris S, Ziegler SF, et al. Sex-associated TSLP-induced immune alterations following early-life RSV infection leads to enhanced allergic disease. Mucosal Immunol. 2019;12(4):969-79.

17. Takahashi K, Shibata T, Akashi-Takamura S, Kiyokawa T, Wakabayashi Y, Tanimura N, et al. A protein associated with Tolllike receptor (TLR) 4 (PRAT4A) is required for TLR-dependent immune responses. J Exp Med. 2007;204(12):2963-76.

18. Takahashi K, Koga K, Linge HM, Zhang Y, Lin X, Metz CN, et al. Macrophage CD74 contributes to MIF-induced pulmonary inflammation. Respir Res. 2009;10:33.

19. Misharin AV, Morales-Nebreda L, Mutlu GM, Budinger GR, Perlman H. Flow cytometric analysis of macrophages and dendritic cell subsets in the mouse lung. Am J Respir Cell Mol Biol. 2013;49(4):503-10.

20. Schyns J, Bureau F, Marichal T. Lung interstitial macrophages: past, present, and future. J Immunol Res. 2018;2018:5160794.

21. Zaynagetdinov R, Sherrill TP, Kendall PL, Segal BH, Weller $\mathrm{KP}$, Tighe RM, et al. Identification of myeloid cell subsets in murine lungs using flow cytometry. Am J Respir Cell Mol Biol. 2013;49(2):180-9.

22. Essilfie AT, Horvat JC, Kim RY, Mayall JR, Pinkerton JW, Beckett EL, et al. Macrolide therapy suppresses key features of experimental steroid-sensitive and steroid-insensitive asthma. Thorax. 2015;70(5):458-67.

23. Beigelman A, Gunsten S, Mikols CL, Vidavsky I, Cannon CL, Brody SL, et al. Azithromycin attenuates airway inflammation in a noninfectious mouse model of allergic asthma. Chest. 2009;136(2):498-506.

24. Kang JY, Jo MR, Kang HH, Kim SK, Kim MS, Kim YH, et al. Long-term azithromycin ameliorates not only airway inflammation but also remodeling in a murine model of chronic asthma. Pulm Pharmacol Ther. 2016;36:37-45.

25. Teran LM, Noso N, Carroll M, Davies DE, Holgate S, Schroder JM. Eosinophil recruitment following allergen challenge is associated with the release of the chemokine RANTES into asthmatic airways. J Immunol. 1996;157(4):1806-12.

26. Hayashi S, Kurdowska A, Miller EJ, Albright ME, Girten BE, Cohen AB. Synthetic hexa- and heptapeptides that inhibit IL-8 from binding to and activating human blood neutrophils. J Immunol. 1995;154(2):814-24.

27. Nishihara F, Nakagome K, Kobayashi T, Noguchi T, Araki R, Uchida Y, et al. Trans-basement membrane migration of eosinophils induced by LPS-stimulated neutrophils from human peripheral blood in vitro. ERJ Open Res. 2015;1(2). 
28. Tang C, Rolland JM, Ward C, Li X, Bish R, Thien F, et al. Modulatory effects of alveolar macrophages on CD4+ T-cell IL-5 responses correlate with IL-1beta, IL-6, and IL-12 production. Eur Respir J. 1999;14(1):106-12.

29. Livermore DM. Bacterial resistance: origins, epidemiology, and impact. Clin Infect Dis. 2003;36(Suppl 1):S11-23.

30. Albrich WC, Monnet DL, Harbarth S. Antibiotic selection pressure and resistance in Streptococcus pneumoniae and Streptococcus pyogenes. Emerg Infect Dis. 2004;10(3):514-7.

31. Jakobsson HE, Jernberg C, Andersson AF, Sjolund-Karlsson M, Jansson JK, Engstrand L. Short-term antibiotic treatment has differing long-term impacts on the human throat and gut microbiome. PLoS ONE. 2010;5(3):e9836.

32. Malhotra-Kumar S, Lammens C, Coenen S, Van Herck K, Goossens $\mathrm{H}$. Effect of azithromycin and clarithromycin therapy on pharyngeal carriage of macrolide-resistant streptococci in healthy volunteers: a randomised, double-blind, placebo-controlled study. Lancet. 2007;369(9560):482-90.

33. Hodge S, Tran HB, Hamon R, Roscioli E, Hodge G, Jersmann $\mathrm{H}$, et al. Nonantibiotic macrolides restore airway macrophage phagocytic function with potential anti-inflammatory effects in chronic lung diseases. Am J Physiol Lung Cell Mol Physiol. 2017;312(5):L678-L687687.

34. Tarran R, Sabater JR, Clarke TC, Tan CD, Davies CM, Liu $\mathrm{J}$, et al. Nonantibiotic macrolides prevent human neutrophil elastase-induced mucus stasis and airway surface liquid volume depletion. Am J Physiol Lung Cell Mol Physiol. 2013;304(11):L746-L756756.

35. Tojima I, Shimizu S, Ogawa T, Kouzaki H, Omura S, Sunazuka $\mathrm{T}$, et al. Anti-inflammatory effects of a novel non-antibiotic macrolide, EM900, on mucus secretion of airway epithelium. Auris Nasus Larynx. 2015;42(4):332-6.

36. Iwanaga N, Nakamura S, Oshima K, Kajihara T, Takazono T, Miyazaki T, et al. Macrolides promote CCL2-mediated macrophage recruitment and clearance of nasopharyngeal pneumococcal colonization in mice. J Infect Dis. 2015;212(7):1150-9.

37. Grissell TV, Powell H, Shafren DR, Boyle MJ, Hensley MJ, Jones $\mathrm{PD}$, et al. Interleukin-10 gene expression in acute virus-induced asthma. Am J Respir Crit Care Med. 2005;172(4):433-9.

38. Hall CB. Respiratory syncytial virus and parainfluenza virus. $\mathrm{N}$ Engl J Med. 2001;344(25):1917-28.

39. Nicholson KG, Kent J, Ireland DC. Respiratory viruses and exacerbations of asthma in adults. BMJ. 1993;307(6910):982-6.

40. Matsumoto K, Inoue H. Viral infections in asthma and COPD. Respir Investig. 2014;52(2):92-100.

41. Kim TB, Kim SY, Moon KA, Park CS, Jang MK, Yun ES, et al. Five-aminoimidazole-4-carboxamide-1-beta-4-ribofuranoside attenuates poly(I:C)-induced airway inflammation in a murine model of asthma. Clin Exp Allergy. 2007;37(11):1709-19.

42. Ujino M, Sugimoto N, Koizumi Y, Ro S, Kojima Y, Asae KH, et al. Leukotriene receptor antagonist attenuated airway inflammation and hyperresponsiveness in a double-stranded RNA-induced asthma exacerbation model. Allergol Int. 2017;66S:S21-S2626.

43. Mahmutovic Persson I, Menzel M, Ramu S, Cerps S, Akbarshahi $\mathrm{H}$, Uller L. IL-1beta mediates lung neutrophilia and IL-33 expression in a mouse model of viral-induced asthma exacerbation. Respir Res. 2018;19(1):16.

44. Lunding LP, Webering S, Vock C, Behrends J, Wagner C, Holscher $\mathrm{C}$, et al. Poly(inosinic-cytidylic) acid-triggered exacerbation of experimental asthma depends on IL-17A produced by NK cells. J Immunol. 2015;194(12):5615-25.

45. Lusamba Kalonji N, Nomura K, Kawase T, Ota C, Kubo H, Sato $\mathrm{T}$, et al. The non-antibiotic macrolide EM900 inhibits rhinovirus infection and cytokine production in human airway epithelial cells. Physiol Rep. 2015;3(10).

46. Sugamata R, Sugawara A, Nagao T, Suzuki K, Hirose T, Yamamoto K, et al. Leucomycin A3, a 16-membered macrolide antibiotic, inhibits influenza A virus infection and disease progression. J Antibiot (Tokyo). 2014;67(3):213-22.

47. Tashiro H, Takahashi K, Sadamatsu H, Kato G, Kurata K, Kimura $\mathrm{S}$, et al. Saturated fatty acid increases lung macrophages and augments house dust mite-induced airway inflammation in mice fed with high-fat diet. Inflammation. 2017;40(3):1072-86.

48. Saradna A, Do DC, Kumar S, Fu QL, Gao P. Macrophage polarization and allergic asthma. Transl Res. 2018;191:1-14.

49. Bhavsar P, Hew M, Khorasani N, Torrego A, Barnes PJ, Adcock I, et al. Relative corticosteroid insensitivity of alveolar macrophages in severe asthma compared with non-severe asthma. Thorax. 2008;63(9):784-90.

50. Bhavsar P, Khorasani N, Hew M, Johnson M, Chung KF. Effect of p38 MAPK inhibition on corticosteroid suppression of cytokine release in severe asthma. Eur Respir J. 2010;35(4):750-6.

51. Gagliardo R, Chanez P, Mathieu M, Bruno A, Costanzo G, Gougat $\mathrm{C}$, et al. Persistent activation of nuclear factor-kappaB signaling pathway in severe uncontrolled asthma. Am J Respir Crit Care Med. 2003;168(10):1190-8.

Publisher's Note Springer Nature remains neutral with regard to jurisdictional claims in published maps and institutional affiliations. 